\title{
The Regional Development Assessment of Social Resilience Based on Quantifiable Analyses Apply to Guangfu Village
}

\author{
Chao Tung $\mathrm{Wu}^{1}$ and Yang Ting Shen ${ }^{2}$
}

\begin{abstract}
This research aims to analyze an organization's social impact under Social Resilience issue (Herb, 2005) by developing the regional development assessment based on ESG standard. In addition, the assessment is also related with Sustainable Development Goal No.11 (Sustainable cities and communities). The application context is using our regional development assessment to evaluate how an organization can interfere when a community suffers external disturbances. This content could be established a sustainable management to arrange concrete consequences from various aspects of perspectives. It is observed that the assessment indicates that how to evaluate social impact of organizations in the community and scientifically quantitate value for Social Resilience. The framework is based on ESG consisting of Environment, Social, and Governance. This estimate proceeds from testing a non-governmental organization (NGO) or a non-profit organization (NPO) interfering with the regions results in how much their influence is and how large a range of their influence is. The assessment was applied to analyze the region-Guangfu Village in Taichung City, Taiwan. The evaluation was not really phenomenal on the appearance under ESG standard. According to this study, the consequences from the assessment are described as below.
\end{abstract}

Keywords: Social Resilience; ESG; Sustainable Development Goal

\section{Introduction}

With the generation renovating increasingly and placing emphasis on social resilience, nations worldwide pay attention to the regional development related to governments, non-government organizations (NGOs), nonprofit organizations (NPOs), empires, and institutions of education. Even the collaboration of interdisciplinary agencies embarks on enhancing benefits of social welfare and taking the initiative with disposing social problems. Especially, abundant wicked problems appear in the society such as aging society, climate change, diseases and so on. In addition, one of the compelling issues associated with the social responsibility in the regional development is how to evaluate the social impact among individual agencies as so to distinguish explicitly their duties.

The purpose of the study is to create an analytic system of social impact below individual agencies in the regions nevertheless the analytic system is only involved in the operation of NGOs and NPOs in Guangfu Village. It not only indicates the social value on the areas but also displays how to distinguish duties and illustrates levels of development of individual agencies. While it is true that applying ESG (Environment, Social, Governance) analysis provides applicable information, it would be uphold via the collaboration of interdisciplinary agencies with motivating local growth. As to the primary goal, the mechanism empowers NGOs and NPOs to control comprehensive 
influences for the assignments in the certain range and therefore the mechanism could be encouraged to define the realistic information with titanic data. Besides, it contains a wide knowledge to instill into the overall aspects of organizations.

Furthermore, the five instructions would instill into ESG analysis in order to lead to an obvious categorization with cautiousness. As a matter of fact, the five instructions oriented with Porter five forces analysis ensure that the analysis originates in a reliable method. Consequently, the performance on social resilience would concretize in the assessment.

The study takes Guangfu Village as an example to establish an adaptive investigation on social resilience in order to maintain the operation of organizations in the regions and enable to respond the practical effectiveness. Moreover, the investigation is able to discern the inner loop and the outer loop containing the merits and weakness beneath the operation of organizations and be utilized its features to inspect the regional development. In particular, NGOs and NPOs have cooperated with other institutions for a period time. It is vital that how to divide individual duties and work efficiently. To propose the stable steps and feasible strategies links to the implement of evaluating the performance of social impact.

\section{Theoretical Framework}

ESG analysis in the regional development would be set up via five instructions. The five instructions are according to Porter five forces analysis made form Michael Porter in 1979, intending to utilize the business analysis to extend the idea of the output in the region. As a result, each instruction would follow up one of main features of five forces analysis to present its meaning on social resilience. In addition, each instruction is expressed how significant it is as below by its feature which is associated with social resilience.

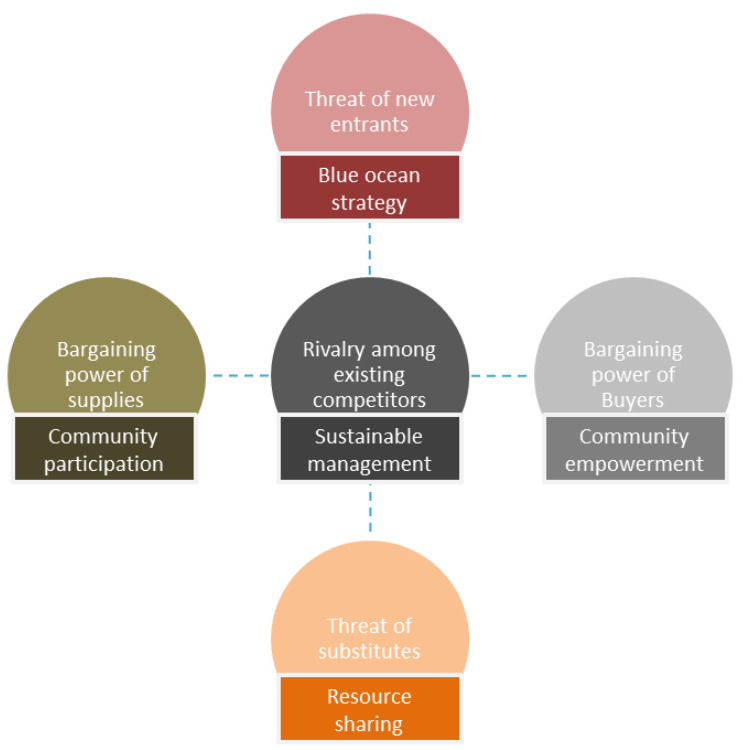


Figure 1 Porter's five forces related with five instructions

Community participation: enhance managements of risk perception for residents.

Since the current surroundings which change rapidly from 'outsiders' and 'insiders' are implemented and described risk in different ways (Larsen, 2011) in inconsistent problem circumstances, the distinction between risk perception and actual risk loses its justification(Beck, 1992). Drawing on complexity theories, the study provides a sensemaking framework on preparing for the unexpected by creating the network that it is capable of building adaptability and transformability, that is, resilience to unknown risks (Cavallo, 2014). Especially, uncertainties in climate change and diversification in local contexts force urban planners to bring into community participation for residents, indigenous knowledge and local characteristics into the resilience assessment (Hung, 2016).

Community empowerment: build spontaneous environmental management.

In many cases, information generation and dissemination projects particularly in the arenas of local community empowerment and environmental management assume a strong knowledge creation component but in reality do not always succeed in generating actionable knowledge (Dewulf, 2005). The critical role of environmental information and knowledge is highlighted within the literature on governance of social resilience. A key issue in this literature is the capability of adaptive governance to guide social-ecological systems towards greater resilience of interconnected human and environmental systems (i.e. the capability to (1) resist shocks, (2) adapt flexibly to constantly changing conditions and (3) to transform when required, in order to keep fulfilling basic ecosystem functions and services) ( Folke, 2010; Karpouzoglou, 2016). Accordingly, the employments or volunteers in the regional institutions organize the local development and preserve the local culture assets. It mainstreams that spontaneous environmental management enables to maintain the thriving and robust.

Sustainable management: operate a self-sustaining business models.

As the business model connects various organizational functions, it is proposed that the tool can also be used more broadly for "sustainable business thinking" (Bocken, 2015). Sustainability addresses the companies' activities to implement sustainable and socialecological requirements across the whole value chain (Rosca, 2017). Given that the regional development can proceed by sufficient funds, organizations need to create a self-sustaining business models with resilient mechanism.

Resource sharing: form a network of sharing information.

In the focus is on sharing the core network, whereas of the work in mainly focuses on wireless resource sharing (Gomez, 2014). A balance of connectivity and modularity in a network are known to contribute to resilience (Gonzalès \& Parrott, 2019). In other words, there is a network of resource sharing in the community therefore it is easy to exchange the information and build a database for regional development.

Blue ocean strategy: possess an ability of expand new markets and future strategies.

Where existing core corporate capabilities and competencies within the organization do not meet these requirements, or inhibitive quantum limitations exist on the availability of such, then a collaborative approach that gives access to new resources that add to the existing knowledge and skills base (potentially a form of transferring of core competencies as intangible resources)can potentially induce the necessary conditions for 
Blue Ocean style strategy development and paradigm change (McLay, 2014). Especially, the institutions in the resilient community are equipped with an ability of seeking blue ocean strategy to support the development.

\section{Part I: The Structure of ESG Analysis with Five Instructions}

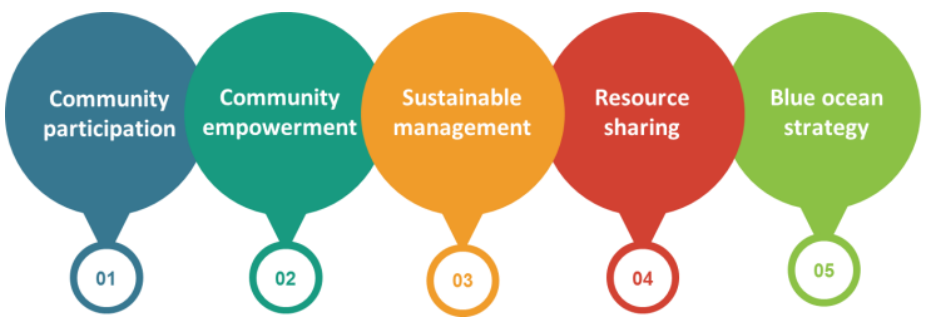

Figure 2 The five instructions

The five instructions associated with the social resilience present the performance of the social impact in the region and even analyze the operations of institutions in the regional development. Furthermore, it is crucial that the operations of institutions are able to be distinguished under the individual instructions. Through the cautious classification, the outcome of institutions could be accurately pointed out the weakness and strength between the external and the internal. Despite the five instructions enable to express the directions of weakness and strength, the approach would not obviously display the causes. Accordingly, the instructions must link to a practical analysis- it dissects the factors from holistic aspects. That is the reason why

ESG analysis corresponds to the standard of assessing the social impact.

ESG analysis depends on the three main topics: environment, social, and governance. It usually assesses the companies whether the companies accord with sustainable corporates. In the past time, ESG analysis was used to evaluating the benefit of companies and some organizations. However, most institutions did not make use of this analysis on the certain areas. In particular, there were enormous institutions which focused on the internal development rather than involving in regions to dissect the social impact. In other words, it is a good opportunity to scope the region with institutions by ESG analysis.

\section{Part II: The Performance on Social Resilience of ESG Analysis with Five Instructions}

This study engages in NGOs or NPOs which works at certain areas to utilize ESG analysis and realize how the institutions implement their plans. An assessment structure related with social resilience is built under the regional development. In addition, ESG analysis would follow the five institutions to progress the specialized items and display the performance on social resilience.

The score of ESG analysis with five instructions is designed as five rankings. The five rankings: much disagree (1 point), somewhat disagree ( 2 points), average ( 3 points), somewhat agree ( 4 points), much agree ( 5 points). 
Table 1: ESG Analysis with Five Instructions based on social resilience

\begin{tabular}{|c|c|c|c|c|c|}
\hline $\begin{array}{r}\text { Five } \\
\text { instructions } \\
\text { ESG } \\
\text { analysis }\end{array}$ & $\begin{array}{l}\text { Community } \\
\text { participation }\end{array}$ & $\begin{array}{c}\text { Community } \\
\text { empowerment }\end{array}$ & $\begin{array}{l}\text { Sustainable } \\
\text { management }\end{array}$ & Resource sharing & $\begin{array}{c}\text { Blue ocean } \\
\text { strategy }\end{array}$ \\
\hline \multirow[t]{2}{*}{ Environment } & $\begin{array}{l}\text { NPO or NGO } \\
\text { holds the } \\
\text { activities of } \\
\text { region and } \\
\text { preserves } \\
\text { environment } \\
\text { with residents. }\end{array}$ & $\begin{array}{l}\text { NPO or NGO } \\
\text { establishes } \\
\text { associations for } \\
\text { preserving } \\
\text { environment. }\end{array}$ & \begin{tabular}{|c|} 
NPO or NGO \\
emphasizes \\
sustainable \\
development \\
oriented for \\
business models.
\end{tabular} & $\begin{array}{l}\text { NPO or NGO } \\
\text { shares the } \\
\text { information on } \\
\text { environmental } \\
\text { issues. }\end{array}$ & $\begin{array}{l}\text { NPO or NGO } \\
\text { organizes the } \\
\text { blueprint with } \\
\text { innovation of } \\
\text { preserving } \\
\text { environment. }\end{array}$ \\
\hline & Score: & Score: & Score: & Score: & Score: \\
\hline \multirow[t]{2}{*}{ Social } & $\begin{array}{l}\text { NPO or NGO } \\
\text { offers suitable } \\
\text { necessaries and } \\
\text { activities for the } \\
\text { residents of } \\
\text { individual ages. }\end{array}$ & \begin{tabular}{|} 
NPO or NGO \\
attaches \\
importance to the \\
decent working \\
environment for \\
cultivating \\
freshmen.
\end{tabular} & $\begin{array}{c}\text { NPO or NGO is } \\
\text { acquired with } \\
\text { adaptive systems } \\
\text { to care the } \\
\text { interests of } \\
\text { employments. }\end{array}$ & \begin{tabular}{|} 
NPO or NGO \\
shares the \\
relative resources \\
of localization \\
with the \\
residents.
\end{tabular} & $\begin{array}{l}\text { NPO or NGO } \\
\text { aims that the } \\
\text { people acquired } \\
\text { with creative } \\
\text { thinking } \\
\text { formulate future } \\
\text { regional } \\
\text { development. }\end{array}$ \\
\hline & Score: & Score: & Score: & Score: & Score: \\
\hline \multirow[t]{2}{*}{ Governance } & $\begin{array}{l}\text { NPO or NGO } \\
\text { emphasizes } \\
\text { equal interests } \\
\text { of the } \\
\text { partnership. }\end{array}$ & \begin{tabular}{|c|} 
NPO or NGO \\
possesses the \\
board \\
composition \\
without undue \\
disruption to \\
achieve missions.
\end{tabular} & $\begin{array}{c}\text { NPO or NGO } \\
\text { manages the } \\
\text { compensation in } \\
\text { the internal } \\
\text { organizations } \\
\text { validly. }\end{array}$ & \begin{tabular}{|c|} 
NPO or NGO \\
maintains \\
favorable \\
cooperation with \\
other \\
shareholders.
\end{tabular} & $\begin{array}{l}\text { NPO or NGO } \\
\text { pays attention on } \\
\text { supporting the } \\
\text { rights of other } \\
\text { shareholders in } \\
\text { the future. }\end{array}$ \\
\hline & Score: & Score: & Score: & Score: & Score: \\
\hline
\end{tabular}

\section{Part III: Quantifiable Analyses Apply to Guangfu Village}

The ESG analysis with five instructions applied in Guangfu Village shows the distinctness in the pilot study. Especially, the subjects who are residents and the workers of NGOs have different opinions on the contribution and social impact of NGOs in Guangfu Village. By the way, the subjects are just few people therefore the pilot study can only express the performance and the functions of the survey at this time. Nevertheless, the survey appears differentiates of the recognition of subjects. From the pilot study, the significant perspectives describe the two aspects; one is inner loop, and another one is outer loop.

The inner loop which focuses on the workers of NGOs indicates that they have almost same opinions on the answers of environment, social, and governance. For the questions of environment, the NGOs seldom not only hold some activities about environmental issues but also emphasize the business model of sustainable development. In contrast, the answers of social display that they tend to assist the regional development via offering the decent working environment for cultivating freshmen and equal rights. Above the description mentioned, it is clear that the tendency point out under the 
survey. Moreover, the difference among three topics is standing out.

The outer loop which focuses on the residents shows that individuals do not approve intensively for the overall questions. Most consider that they have no idea what the NGOs did in the region. According to their answers, it is easy to realize residents' acknowledges on the content of NGOs whether they had practically contacted with local NGOs. In other words, the survey can prove that providing adaptive questions for residents is one of vital functions through this example. In fact, the ESG analysis with five instructions is equipped with determining the suitable information for subjects.

Design the Structure of this assessment in order to test the pilot study in Guangfu Village. Furthermore, the pilot study actually contributes its attributes. Not only evaluate the three topics of ESG analysis with five instructions but also present the reference of the inner loop and the outer loop. Besides, the most important of the pilot study brings into another contributes, building levels of the survey to adapt the current development and subjects. Accordingly, it cannot cause that some subjects are not able to understand the content of the survey.

\section{Conclusion}

From the example such as Guangfu Village, the information indicated that the analysis could performance the weakness and strength in the primary five instructions. Therefore, the organization which was evaluated by the assessment knows what the significant missions will be implemented in the future plan.

The pilot study provides the reliable data for this assessment and promotes the design of the assessment. In particular, how to establish levels of the survey for the current development and subjects is a critical factor to create adaptive investigations. As a result, the survey enables to discuss the aspects of environment, social, and governance.

Due to the pilot study, it experienced that how to progress the ESG analysis with five instructions is suitable for social resilience under the regional development. In the past, ESG analysis generally was taken advantage of assessing the social impact from companies and institutions, not to engage in regional development. Therefore, adjusting the structure of ESG analysis is input in the region for the study.

After that, ESG analysis comes out the performance on social resilience, and then the next step is using Social Return on Investment (SROI) to investigate deeply on the projects of organizations. SROI system which is another analysis enables to extend projects to projects, not just to develop on the performance. In short, SROI can scope the movements of institutions via concrete data.

\section{References}

Beck, U. (1992). Risk society: Towards a new modernity (Vol. 17). sage.

Bocken, N. M. P., Rana, P., \& Short, S. W. (2015). Value mapping for sustainable business thinking. Journal of Industrial and Production Engineering, 32(1), 67-81.

Caplan, L., Griswold, J. S., \& Jarvis, W. F. (2013). From SRI to ESG: The Changing World of Responsible Investing. Commonfund Institute.

Cavallo, A., \& Ireland, V. (2014). Preparing for complex interdependent risks: a system of systems approach to building disaster resilience. International journal of disaster risk reduction, 9, 181-193. 
Dewulf, A., Craps, M., Bouwen, R., Abril, F., \& Zhingri, M. (2005). How indigenous farmers and university engineers create actionable knowledge for sustainable irrigation. Action research, 3(2), 175-192.

Escrig-Olmedo, E., Muñoz-Torres, M. J., \& Fernandez-Izquierdo, M. A. (2010). Socially responsible investing: sustainability indices, ESG rating and information provider agencies. International journal of sustainable economy, 2(4), 442-461.

Folke, C., Carpenter, S., Walker, B., Scheffer, M., Chapin, T., \& Rockström, J. (2010). Resilience thinking: integrating resilience, adaptability and transformability. Ecology and society, 15(4).

Gomez, K., Goratti, L., Rasheed, T., \& Reynaud, L. (2014). Enabling disaster-resilient 4G mobile communication networks. IEEE Communications Magazine, 52(12), 66-73.

Gonzalès, R., \& Parrott, L. (2019). How Stakeholders Structure their Collaborations to Anticipate and Tackle the Threat of Mountain Pine Beetle in the Jasper/Hinton (Alberta, Canada) Area. Canadian Journal of Forest Research, (ja).

Hung, H. C., Yang, C. Y., Chien, C. Y., \& Liu, Y. C. (2016). Building resilience: Mainstreaming community participation into integrated assessment of resilience to climatic hazards in metropolitan land use management. Land Use Policy, 50, 48-58.

Karpouzoglou, T., Zulkafli, Z., Grainger, S., Dewulf, A., Buytaert, W., \& Hannah, D. M. (2016). Environmental virtual observatories (EVOs): prospects for knowledge co-creation and resilience in the information age. Current Opinion in Environmental Sustainability, 18, 40-48.

Larsen, R. K., Calgaro, E., \& Thomalla, F. (2011). Governing resilience building in Thailand's tourismdependent coastal communities: Conceptualising stakeholder agency in social-ecological systems. Global Environmental Change, 21(2), 481-491.

Lyon, C., \& Parkins, J. R. (2013). Toward a social theory of resilience: social systems, cultural systems, and collective action in transitioning forest- based communities. Rural Sociology, 78(4), 528-549.

Lokuwaduge, C. S. D. S., \& Heenetigala, K. (2017). Integrating environmental, social and governance (ESG) disclosure for a sustainable development: An Australian study. Business Strategy and the Environment, 26(4), 438-450.

McLay, A. (2014). Re-reengineering the dream: agility as competitive adaptability. International Journal of Agile Systems and Management, 7(2), 101-115.

Pembleton, C. J. (2018). Creating Revenue Diversification Among Nonprofits.

Rosca, E., Arnold, M., \& Bendul, J. C. (2017). Business models for sustainable innovation-an empirical analysis of frugal products and services. Journal of Cleaner Production, 162, S133-S145. 